\title{
Critical success factors for implementing risk management systems in developing countries
}

\author{
M. Reza Hosseini ${ }^{1}$, Nicholas Chileshe ${ }^{2}$, Jacqueline Jepson ${ }^{2}$ and Mehrdad Arashpour ${ }^{3}$ \\ ${ }^{1}$ Deakin University, Australia \\ ${ }^{2}$ University of South Australia, Australia \\ ${ }^{3}$ RMIT University, Australia
}

\begin{abstract}
A review of published studies on risk management in developing countries reveals that critical success factors for implementing risk management has remained an under-researched area of investigation. This paper is aimed at investigating the perceptions of construction professionals concerning the critical success factors (CSFs) for implementation of risk management systems (IRMS). Survey data was collected from 87 construction professionals from the Iranian construction industry as a developing country. The results indicate that four factors are regarded as highly critical: 'support from managers', 'inclusion of risk management in construction education and training courses for construction practitioners', 'attempting to deliver projects systematically', and 'awareness and knowledge of the process for implementing risk management'. Assessing the associations among CSFs also highlighted the crucial role of enhancing the effectiveness of knowledge management practices in construction organisations. Study also revealed that parties involved in projects do not agree on the level of importance of CSFs for implementing risk management in developing countries. This study contributes to practice and research in several ways. For practice, it increases understanding of how closely knowledge management is associated with the implementation of risk management systems in developing countries. For research, the findings would encourage construction practitioners to support effective knowledge management as a precursor to higher levels of risk management implementation on construction projects.
\end{abstract}

Keywords: Critical success factors, risk management, the construction industry, developing countries.

Paper type: Research article

\section{Introduction}

Construction projects in developing countries are prone to a wide range of uncertainties (Ebrahimnejad, Mousavi and Seyrafianpour, 2010), including construction practitioners lacking the prerequisite skills (Akhavan Tabassi and Bakar, 2009) and market volatilities (Fereidouni, 2011). Many such problems are preventable through the implementation of effective risk management in projects (Tadayon, Jaafar and Nasri, 2012). Nevertheless, as aptly postulated by Tadayon, Jaafar and Nasri (2012) developing countries have not adequately focused on risk management. In essence, risk management is not regarded as a priority for delivering construction projects (Ghahramanzadeh, 2013; Tadayon, Jaafar and Nasri, 2012). As observed by

Copyright: Construction Economics and Building 2016. (C) 2016 Reza Hosseini, Nicholas Chileshe, Jacqueline Jepson and Mehrdad Arashpour. This is an Open Access article distributed under the terms of the Creative Commons Attribution 4.0 Unported (CC BY 4.0) License (https://creativecommons.org/licenses/by/4.0/), allowing third parties to copy and redistribute the material in any medium or format and to remix, transform, and build upon the material for any purpose, even commercially, provided the original work is properly cited and states its license.

Citation: Hosseini, M. R., Chileshe, N., Jepson, J., and Arashpour, M. 2016. Critical success factors for implementing risk management systems in developing countries, Construction Economics and Building, 16(1), 18-32. DOI: http://dx.doi.org/10.5130/AJCEB.v16i1.4651.

Corresponding author: M. Reza Hosseini; Email - Reza.Hosseini@deakin.edu.au

Publisher: University of Technology Sydney (UTS) ePress 
the recent study by Bowers and Khorakian (2014), hitherto little evidence of successful applications of risk management systems is available within the construction industries in developing countries.

In view of such scant attention being paid to the implementation of risk management, researchers have instead focused on promoting the adoption and implementation of risk management systems in developing countries (Ghadak Zadeh, 2010; Ghahramanzadeh, 2013). To evaluate the success of these systems, the appropriate first step is to identify the critical success factors for Implementation of Risk Management Systems (IRMS) in developing countries. Yet, little information with regard to actual risk management implementation systems is available from developing countries (Iqbal et al., 2015). The existing studies on risk management in developing countries e.g. (Iqbal et al., 2015; KarimiAzari et al., 2011; Mojtahedi, Mousavi and Makui, 2010) have almost entirely concentrated on identifying and evaluating risks rather than the systems applied. While the few available studies on critical success factors associated with risk management in developing countries, e.g. the study by Chileshe and Kikwasi (2014), have focused exclusively on one particular country.

Against this background, investigating of the CSFs for IRMS in construction projects, their interactions and subsequent impact on project success is an overlooked area of study in almost all developing countries (Chileshe and Kikwasi, 2013; 2014; Perera et al., 2014). In essence, exploring the perceptions of construction practitioners with regard to prerequisites of implementing risk management systems in developing countries has remained an area in need of investigation (Iqbal et al., 2015). Addressing these things has been the driving force behind conducting the present study. To this end, the following section of this paper presents an overview of studies that have presented findings associated with critical success factors of risk management implementation in developing countries. The subsequent sections explain the methodological approach, findings and implications of the study. Conclusion, including recommendations of the study for further investigations, is presented at the end.

\section{Literature review}

In reviewing the relevant literature, firstly a summary of barriers and critical success factors for implementing risk management on construction projects is presented. Secondly, equivalent studies in relevant disciplines such as knowledge management are included. Most importantly, the underlying assumptions undertaken in the reviewed studies are examined and discussed. Table 1 presents a summary of selected studies on the antecedents, CSFs and barriers to IRMS. The eleven factors listed in Table 1 have been found critical to IRMS in the construction industries of developing countries such as Malaysia, Iran and Pakistan. As illustrated in Table 1, Goh and Abdul-Rahman (2013) attributed the 'lack of support' and 'inconsistency among different parties' mostly to the lack of knowledge among construction practitioners in relation to potential benefits of IRMS in their projects. It could thus be inferred that these factors are necessary for effective implementation of risk management systems.

In the areas of disaster management, Brown and Fallahi (2008) analysed the extent to which opportunities were capitalised upon and proposed strategies and recommendations for future risk preparedness planning in Bam, Iran. That is, the earthquake provided an opportunity for further development and growth of the city's unique and internationally known date production through more publicity, renovation of the old irrigation systems, and expansion of its related industries. It could be argued that any study investigating future risk preparedness would be akin to attempting to deliver projects systematically (CSFs7). Conversely, education programs have been suggested as a mechanism for increasing the public awareness and preparedness for earthquakes in Iran (Akhavan Tabassi and Bakar, 2009; Parsizadeh and Ghafory-Ashtiany, 2010). These findings can thus be linked to this study of CSFs. 
Table 1: Summary of selected studies on antecedents (CSFs and barriers) to risk management and allied disciplines

\begin{tabular}{|c|c|c|}
\hline No. & CSFs as used in this study & Previous studies \\
\hline CSF1 & Support from managers & $\begin{array}{l}\text { (Jafari et al., 2011)*; ((Goh and Abdul-Rahman, } \\
\text { 2013) ; (Ram and Corkindale, 2014) }\end{array}$ \\
\hline CSF2 & $\begin{array}{l}\text { Awareness and knowledge of the process for } \\
\text { implementing RM }\end{array}$ & $\begin{array}{l}\text { (Frimpong, Oluwoye and Crawford, 2003); (Kim } \\
\text { and Bejaj, 2000); (Santoso, Ogunlana and } \\
\text { Minato, 2003); (Lyons and Skitmore, 2004); } \\
\text { (Zou and Li, 2010); (Cagliano, Grimaldi and } \\
\text { Rafele, 2015) }\end{array}$ \\
\hline CSF3 & $\begin{array}{l}\text { Promoting collaboration \& } \& \text { culture } \\
\text { environment among involved parties }\end{array}$ & $\begin{array}{l}\text { (Jafari et al., 2011)*; (Akhavan Tabassi et al., } \\
\text { 2014); (Ram and Corkindale, 2014)e }\end{array}$ \\
\hline CSF4 & $\begin{array}{l}\text { Request for IRMS on projects by clients and } \\
\text { end users }\end{array}$ & $\begin{array}{l}\text { Johnson and Scholes, 1999); (Kim and Bejaj, } \\
\text { 2000) }\end{array}$ \\
\hline CSF5 & $\begin{array}{l}\text { Incorporating IRMS among the strategic } \\
\text { objectives of organisations involved in } \\
\text { projects }\end{array}$ & $\begin{array}{l}\text { (Bowers and Khorakian, 2014); (Pinto and } \\
\text { Covin, 1989); (Kog and Loh, 1999); (Ram and } \\
\text { Corkindale, 2014) }\end{array}$ \\
\hline CSF6 & $\begin{array}{l}\text { Taking into account the effects of the } \\
\text { business environment surrounding projects }\end{array}$ & $\begin{array}{l}\text { (Bowers and Khorakian, 2014)b; (Pinto and } \\
\text { Covin, 1989); (Belassi and Tukel, 1996); (Kog } \\
\text { and Loh, 1999); (Ika, Diallo and Thuillier, 2011); } \\
\text { (Ram and Corkindale, 2014) }^{\text {e }}\end{array}$ \\
\hline CSF7 & Attempting to deliver projects systematically & (Fallahi, 2008)' ${ }^{\mathrm{e}}$ (Ghoddousi et al., 2015) \\
\hline CSF8 & $\begin{array}{l}\text { Promoting team working and effective } \\
\text { communication among the parties involved }\end{array}$ & $\begin{array}{l}\text { (Jafari et al., 2011)* (Choudhry and Iqbal, 2013); } \\
\text { (Goh and Abdul-Rahman, 2013)d; (Ram and } \\
\text { Corkindale, 2014) }\end{array}$ \\
\hline CSF9 & $\begin{array}{l}\text { Access to risk management systems } \\
\text { consultants }\end{array}$ & (Pinto and Covin, 1989); (Kog and Loh, 1999) \\
\hline CSF10 & $\begin{array}{l}\text { Factoring in the costs of IRMS within } \\
\text { project's budgets }\end{array}$ & $\begin{array}{l}\text { (Tadayon, Jaafar and Nasri, 2012); (Ram and } \\
\text { Corkindale, 2014) }\end{array}$ \\
\hline CSF11 & $\begin{array}{l}\text { Inclusion of risk management systems } \\
\text { among education and training subjects of } \\
\text { construction practitioners }\end{array}$ & $\begin{array}{l}\text { (Parsizadeh and Ghafory-Ashtiany, 2010)a; } \\
\text { (Tadayon, Jaafar and Nasri, 2012); (Jafari et al., } \\
\text { 2011); (Choudhry and Iqbal, 2013) } \text {; (Ram and } \\
\text { Corkindale, 2014) }\end{array}$ \\
\hline
\end{tabular}

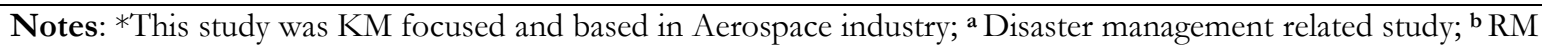
related study; ${ }^{\mathrm{c}}$ Pakistan related RM study; d Malaysian related RM study; The highlighted (in bold) CSFs and previous studies further draws upon the literature review as previously published by Chileshe and Kikwasi (2014) and therefore not listed in the end-text references. This was largely drawn from both developed and developing countries; ${ }^{\mathrm{e}}$ List of factors obtained from the study by Ram and Corkindale (2014) review within the enterprise resource planning (ERP) study.
\end{abstract}

Table 1 also shows some examples of antecedents and CSFs in industries such as aerospace and fields of knowledge management as highlighted by Jafari et al. (2011). The rationale for including knowledge management is due to its relationships with risk management systems in aspects such as lessons learnt. The study by Jafari et al. (2011) aimed at discussing the essential issues of knowledge management adoption. The following essential factors for knowledge management were identified: (1) team working and knowledge management features; (2) leadership and commitment of CEO; (3) appropriate organisational infrastructure; (4) pilot, benchmarking and knowledge systems; (5) job enrichment and security; (6) culture, change management and strategy; (7) collaborative and flexible organisation; and (8) training and learning.

Examination of Table 1 shows that whereas the literature review was conducted to provide a summary of CSF for risk management systems utilising a range of studies, it also included a review of related studies in knowledge management and resource planning. The argument for conducting this process was the lack of relevant articles on risk management systems relating to CSF. Furthermore, support and justification for inclusion of knowledge management studies can 
be found in the study by Cagliano, Grimaldi and Rafele (2015) that highlighted the importance of communication and knowledge creation when dealing with uncertainty. Lessons learnt have also been suggested in risk management systems literature as a mechanism for reducing the cost and time necessary for implementing risk management systems (Tadayon, Jaafar and Nasri, 2012). Similarly, the study by Jafari et al. (2011) aimed at developing a model for risk management systems which incorporated the concept of knowledge loss within the Iranian project based organisations, this model was intended for use when assessing risk for the project.

Further studies relate to the CSFs associated with risk sensitive culture and collaborative environment (Table 1: CSFs3). Some specific Iranian studies e.g. the paper by Akhavan Tabassi et al. (2014) highlighted the significance of the cooperation of team members for executing knowledge management. This same assertion could be extended to RM implementation. Support for enhanced culture through formalisation of risk management procedures is further provided by Tadayon, Jaafar and Nasri (2012). The study suggested that this could be achieved by putting in place compulsory framework for IRMS in construction projects by relevant authorities.

Other CSFs included in Table 1 are drawn from the study by Ram and Corkindale (2014). The former study aimed at examining the literature on enterprise resource planning (ERP) to establish whether the CSFs for achieving stages of an ERP project have been empirically shown to be 'critical'. The identified CSFs were categorised into 4 groups: (1) organisational-related; (2) technological/ERP-related; (3) project-related; and (4) individual-related. One justification for including some of the CSFs and assumptions is relevance to the objectives of the present study. Ram and Corkindale (2014) argued that, conceptually, the criticalness of the factor could only be established when it was empirically shown that it influenced the performance of firms to achieve a desired outcome. Using that premise, the CSFs adopted in this study are assumed to have an impact on project outcomes, delivery or performance criteria. Examples of this are suggested by Tadayon, Jaafar and Nasri (2012, p.57) and include the following: undertaking projects within the cost estimate or budget, within original estimated construction period or required competition date, and achieving the required quality and operational requirements.

\section{Research method}

The study selected the Iranian construction industry as the most fitting context for exploring the critical success factors to risk management implementation in developing countries. This decision was made based on the viewpoints supported by Pournader, Tabassi and Baloh (2015) who referred to the weight of the construction industry in Iran's economy. Their arguments were built on the amount of investment and size of the construction industry in Iran in comparison to a wide range of other developing countries. Besides, the ease of access to data for the researchers was another motive for considering Iran as the context of the study. Added to this is the great potential envisaged for improvement by the introduction of CSFs for risk management systems within the Iranian context, which further justifies the abovementioned decision.

The basis of the questionnaire for this study was adapted from a validated instrument i.e. the questionnaire deployed by Chileshe and Kikwasi (2014) within the Tanzanian context. According to Carless and De Paola (2000) adapting and customising available instruments for specific environments targeted by a research study is acceptable. The questionnaire required translation (from English into Persian and vice versa) and a review of the items contained therein. The procedure undertaken in the translation and review of the questionnaire complied with the protocol suggested by Marsick and Watkins (2003). This comprised four steps: (1) forward translation; (2) assessment; (3) backward translation; and (4) assessment based on the yardsticks of clarity, common language, and cultural adequacy. As part of the identified four-step procedure, the basic instrument was presented to 4 Iranian project managers each with more than 12 years of experience on construction projects. The questionnaire was approved by the 
project managers, with their suggestion that technical terms (e.g. risk management terminology) should be fully clarified. Thus, central definitions were added to the questionnaire to make objectives clear for potential respondents. The rationale in submitting the questionnaire to the Iranian project managers is further supported by Forza (2002), who recognised 'industry experts' among three types of people who should be involved in the pre-testing of the questionnaire.

The first section of the questionnaire included the overarching aims of the research projects and covered the demographics, whereas the second section included the eleven CSFs identified in Table 1 (CSF1 - CSF 11). In line with the study by Chileshe and Kikwasi (2014), the respondents were asked to rate and identify the CSFs they perceived as necessary for IRMS. A five-point Likert-scale was used to elicit these opinions where $(1=$ strongly disagree, $2=$ disagree, $3=$ neutral, $4=$ agree, and $5=$ strongly agree).

\section{Data analysis}

The use of Likert-scale data has become an acceptable practice among the published studies (Healey, 2008). The scale in the present study was a five-point scale and Byrne (2001) argued that it makes sense to use categorical data as if they are continuous as long as the number of categories for each variable is not below five. As postulated by Bentler and Chou (1987) when a variable has four or more categories the results of statistical analysis are not significantly distorted. Yet use of standard deviation for Likert-scale data is not recommended and applying parametric statistical methods depends on establishing the normality of the data (Purdey, 2013). That is, parametric methods have underlying assumptions about normality and are permissible for use as long as variables meet the requirements about the shape of the distribution. Test of normality of variables showed that variables in the dataset have non-normal distributions; therefore non-parametric tests were applied for analysis of data as described next.

The measurement instrument was also tested for validity as recommended by Forza (2002). Accordingly, the test of internal consistency of the survey was conducted using reliability analysis. The Cronbach alpha was found to be 0.882 for the pool of variables, which was greater than 0.7 , thus indicating a high reliability of scales.

\section{Results}

\section{Sample demographic attributes}

The lists of certified companies were downloaded from the data bank of licensed construction companies. These were merged and sorted alphabetically. Afterwards, a random selection among the outcome was done by using a non-replacement random selection technique. 494 invitations to participate in the research study were sent by post to the list of companies with an invitation to distribute the questionnaire among their employees. Follow up calls were conducted which resulted in receiving 87 completed questionnaires. The process of preparing the list, data collection and entering data took 7 months and was completed at the end of May 2013.

As illustrated in Table 2, the proportions of the respondents in terms of years of experience were: less than 5 years $(31.4 \%)$; $5-10$ years $(30.2 \%)$; $11-15$ years $(22.1 \%)$; and more than 15 years $(16.3 \%)$. The proportions of the respondents in terms of professional background (not shown in Table 2) were: $15.1 \%$ (13) Project managers; $20.9 \%$ (18) design engineers; $33.7 \%$ (29) supervisors; $12.6 \%$ (11) site managers; and others $17.2 \%$ (15). The length of service and the position of respondents were regarded as evidence of the breadth of their knowledge regarding the strategic and operational levels in the Iranian construction industry. Thus, the sample was deemed adequately knowledgeable on the topic of the inquiry. 
Table 2: Profile of the survey's respondents

\begin{tabular}{|c|c|c|c|c|c|c|}
\hline \multirow[t]{2}{*}{ Company's role } & & \multicolumn{4}{|c|}{$\begin{array}{c}\text { Experience in the Iranian construction industry } \\
\text { (years) }\end{array}$} & \multirow[t]{2}{*}{ Total } \\
\hline & & $\begin{array}{l}\text { Fewer } \\
\text { than } 5\end{array}$ & $\begin{array}{c}5-10 \\
\text { years }\end{array}$ & $\begin{array}{l}11-15 \\
\text { years }\end{array}$ & $\begin{array}{l}\text { More } \\
\text { than } 15\end{array}$ & \\
\hline Client & Count & 5 & 9 & 5 & 8 & 27 \\
\hline Consultant & Count & 11 & 10 & 6 & 4 & 31 \\
\hline Contractor & Count & 11 & 7 & 8 & 2 & 29 \\
\hline \multirow{2}{*}{ Total } & Count & 27 & 26 & 19 & 14 & 87 \\
\hline & $\%$ of Total & $31.4 \%$ & $30.2 \%$ & $22.1 \%$ & $16.3 \%$ & $100.0 \%$ \\
\hline
\end{tabular}

The breakdown of the final respondents according to the role in the construction industry (see Table 2) was as follows: majority (31) were consultants followed by 28 contractors and 27 clients. The contractor grouping also included 1 specialist sub-contractor and 1 operator, which were included in this 'contractor' grouping due to their limited numbers.

\section{Test of normality for variables}

Shapiro-Wilk test is based on assessing the correlation between the data at hand and the corresponding normal scores. This test is regarded as the best choice for testing the normality of variables (Ghasemi and Zahediasl, 2012). The results of conducting the test for available data showed that all the variables in the dataset follow a non-normal distribution with the statistic for

Shapiro-Wilk test ranging from 706 to 852 ( $d f=87, p=0.00<0.05)$. This indicated that distributions of variables were not normal, thus use of parametric tests would culminate in distorted and misleading results (Ghasemi and Zahediasl, 2012; Purdey, 2013). Therefore, nonparamedic methods, which have no assumption regarding the distribution of data were utilised.

\section{Ranking of CSFs by Contractors, Clients and Consultants}

Use of RII for assessing the relative importance of a variables in a pool of similar items is an acceptable and widespread technique within construction research (Holt, 2014). Besides, this method is not based on mean and standard deviation of variables, which were deemed not fitting the variables in the dataset with non-normal distributions (Purdey, 2013). Calculations for defining RII for each variable were performed according to Equation 1.

$$
R I I=\frac{1 n_{1}+2 n_{2}+3 n_{2}+4 n_{4}+5 n_{3}}{A \times N}
$$

Equation 1

Where: $n_{1}, n_{2}, n_{3}, n_{4}, n_{5}$ were corresponding number of respondents, which scored each of the items on the scale (from 1 to 5 ). $N$ was the total number of respondents for each variable and $A$ is the largest integer on the scale range ( 5 for the present study). Table 3 summarises the results of the analyses of the CSFs based on the overall sample and group-wise ratings of the respondents (contractors', clients', and consultants).

Based on the overall sample, 'support from managers' was found to be the item with the highest relative impotence $(\mathrm{RII}=0.878)$. Overall, "inclusion of risk management among education and training subjects of construction practitioners", was given the second highest rating. Both contractors and clients agreed with this relative importance and ranked this CSF as the second, whereas the consultants ranked it as the $6^{\text {th }}$ implying the lack of importance assigned to this factors by consultants. 
Table 3: Group-wise ratings of CSFs (overall and according to the role of organisations)

\begin{tabular}{|c|c|c|c|c|c|c|c|c|c|c|c|c|}
\hline \multirow[t]{2}{*}{ CSFs for risk management } & \multicolumn{3}{|c|}{ Overall } & \multicolumn{3}{|c|}{ Contractors } & \multicolumn{3}{|c|}{ Clients } & \multicolumn{3}{|c|}{ Consultants } \\
\hline & Z & 路 & 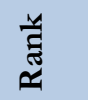 & Z & 止 & 莞 & 乙 & $\exists$ & $\underset{\text { Е }}{\tilde{I}}$ & Z & $\underset{ح}{\Xi}$ & 气ี \\
\hline CSF1 = Support from managers & 87 & 0.878 & 1 & 29 & 0.897 & 1 & 27 & 0.889 & 1 & 31 & 0.852 & 4 \\
\hline $\begin{array}{l}\text { CSF } 11=\text { Inclusion of risk management among education and training subjects } \\
\text { of construction practitioners }\end{array}$ & 87 & 0.867 & 2 & 29 & 0.890 & 2 & 27 & 0.852 & 2 & 31 & 0.845 & 6 \\
\hline $\begin{array}{l}\text { CSF } 8=\text { Promoting team working and effective communication among parties } \\
\text { involved }\end{array}$ & 87 & 0.851 & 3 & 29 & 0.855 & 3 & 27 & 0.807 & 5 & 31 & 0.884 & 1 \\
\hline CSF7 $=$ Attempting to deliver projects systematically & 87 & 0.841 & 4 & 29 & 0.848 & 4 & 27 & 0.785 & 3 & 31 & 0.871 & 2 \\
\hline $\mathrm{CSF} 2=$ Awareness and knowledge of the process for IRMS & 87 & 0.841 & 5 & 29 & 0.841 & 5 & 27 & 0.837 & 7 & 31 & 0.845 & 5 \\
\hline CSF3= Promoting collaboration culture environment among involved parties & 87 & 0.839 & 6 & 29 & 0.834 & 6 & 27 & 0.815 & 4 & 31 & 0.865 & 3 \\
\hline CSF9 $=$ Access to IRMS consultants & 87 & 0.811 & 7 & 29 & 0.814 & 7 & 27 & 0.778 & 8 & 31 & 0.813 & 9 \\
\hline CSF4=Request for IRMS in projects by clients and end users & 87 & 0.809 & 8 & 29 & 0.772 & 9 & 27 & 0.800 & 6 & 31 & 0.826 & 8 \\
\hline CSF10 $=$ Factoring in the costs of IRMS within project budgets & 87 & 0.802 & 9 & 29 & 0.786 & 8 & 27 & 0.756 & 9 & 31 & 0.832 & 7 \\
\hline $\begin{array}{l}\text { CSF5 = Incorporating IRMS among the strategic objectives of organisations } \\
\text { involved in projects }\end{array}$ & 87 & 0.756 & 10 & 29 & 0.759 & 10 & 27 & 0.748 & 10 & 31 & 0.748 & 11 \\
\hline $\begin{array}{l}\text { CSF6 = Taking into account the effects of business environment surrounding } \\
\text { projects. }\end{array}$ & 87 & 0.756 & 11 & 29 & 0.738 & 11 & 27 & 0.689 & 11 & 31 & 0.806 & 10 \\
\hline
\end{tabular}


"Attempting to deliver projects systematically", "Awareness and knowledge of the process for IRMS" and "Promoting team working and effective communication among parties involved" were regarded as the $3^{\text {rd }}$ to the $5^{\text {th }}$ most important items according to the overall ranking. There was a contrast of views, the consultants rated this CSFs as the most important (RII=0.884), whereas the contractors ranked 'Promoting team working and effective communication among parties involved" as the third $(\mathrm{RII}=0.855)$, while clients ranked it as the 5th among factors. Therefore, consultants' rating was the highest among the three groupings. Besides, "Awareness and knowledge of the process for IRMS" was ranked 7th by clients. "Access to IRMS consultants" was generally accepted by the groups as a critical success factor but with an importance rank of $7^{\text {th }}$ to $9^{\text {th }}$ implying that this is not of great significance for Iranian construction practitioners. "Request for IRMS in projects by clients and end users" and "Factoring in the costs of IRMS within project budgets" were also regarded as the $8^{\text {th }}$ and $9^{\text {th }}$ according to the overall ranking. Conversely clients ranked "Request for IRMS in projects by clients and end users" as the $6^{\text {th }}$ denoting their views regarding the crucial role of clients for implementing risk management on projects.

On the other hand, 'taking into account the effects of the business environment surrounding projects' was regarded as the least ranked $(\mathrm{RII}=0.756)$ overly and for 3 main groups involved in the study (e.g. contractors, consultants and clients). Likewise, "Incorporating IRMS among the strategic objectives of organisations involved in projects" was ranked as the $10^{\text {th }}$ by all the three groups similar to the overall ranking assigned to this factor.

A number of discrepancies were observed between the rankings of three groups involved in the survey as discussed above. This necessitated investigating whether the overall ranking is applicable to the general population. This necessitated identifying if the observed differences in the dataset are statistically significant among three different roles. Conducting such a test was of paramount importance because a significant test result would necessitate suggesting different rankings for different roles and questioned the validity of overall ranking within the industry.

\section{Impact of Company's role}

The inferential analysis of the present study entailed investigating whether a company's role in the construction industry has any influence on the perceptions of the practitioners associated with the critical success factors to risk implementation systems in Iran. To this end, company's roles in the construction industry (as illustrated in Table 2) were regarded as independent variables while CSFs were considered the dependents variables. This encompasses conducting a Kruskal-Wallis $H$ test, which is able to determine whether or several independent items come from the same population. This is the non-parametric equivalent of one-way ANOVA and has no certain assumptions regarding the distribution of variables (Cronk, 2014). The null hypothesis to be tested here was defined as below.

\section{$H_{0}=$ the perceptions of construction practitioners with regard to CSFs are similar across the three different roles}

The results of the test are illustrated in Table 4. As inferred from Table 4, the perceptions of all three groups for all the CSFs except for CSF6 were similar across the three roles of construction

practitioners involved in the survey. A significant result $\left(H(2)=6.617_{s} p=0.037<.05\right)$ was found for CFS6 indicating that the three groups differed from each other on their perception regarding the importance of CSF6. Follow-up pair-wise comparisons showed that the pair clients-consultants are significantly different when it comes to their perceptions with regard to

CSF6 (test statistics $=-15.820$, Adjusted Sig. $=0.031<.05$ ). 
Table 4: Evaluating the impacts of role on perceived CSFs

\begin{tabular}{lccl}
\hline & & \multicolumn{2}{c}{ Independent samples Kruskal-Wallis test } \\
\cline { 2 - 4 } CSFs & Test statistic $(d f=2)$ & Sig. & Outcome \\
\cline { 2 - 4 } CFS1 & 1.786 & .409 & Retain the $H_{0}$ hypothesis \\
CFS2 & .158 & .924 & Retain the $H_{0}$ hypothesis \\
CFS3 & 1.022 & .600 & Retain the $H_{0}$ hypothesis \\
CFS4 & .773 & .679 & Retain the $H_{0}$ hypothesis \\
CFS5 & .274 & .872 & Retain the $H_{0}$ hypothesis \\
CFS6 & 6.617 & $.037^{*}$ & Reject the $H_{0}$ hypothesis \\
CFS7 & 6.043 & .05 & Retain the $H_{0}$ hypothesis \\
CFS8 & 2.441 & .295 & Retain the $H_{0}$ hypothesis \\
CFS9 & 2.065 & .356 & Retain the $H_{0}$ hypothesis \\
CFS10 & 2.380 & .304 & Retain the $H_{0}$ hypothesis \\
CFS11 & 2.102 & .350 & Retain the $H_{0}$ hypothesis
\end{tabular}

*Note: The significance level is .05

\section{Associations among CSFs}

To assess the strength of associations among the CSFs, a correlation matrix as illustrated in Figure 1 was produced. The method was Spearman correlation which assessed the strength of relationships between two variables. This methods works based on the ranks of variables and has no required assumption regarding the distribution of data (Cronk, 2014).

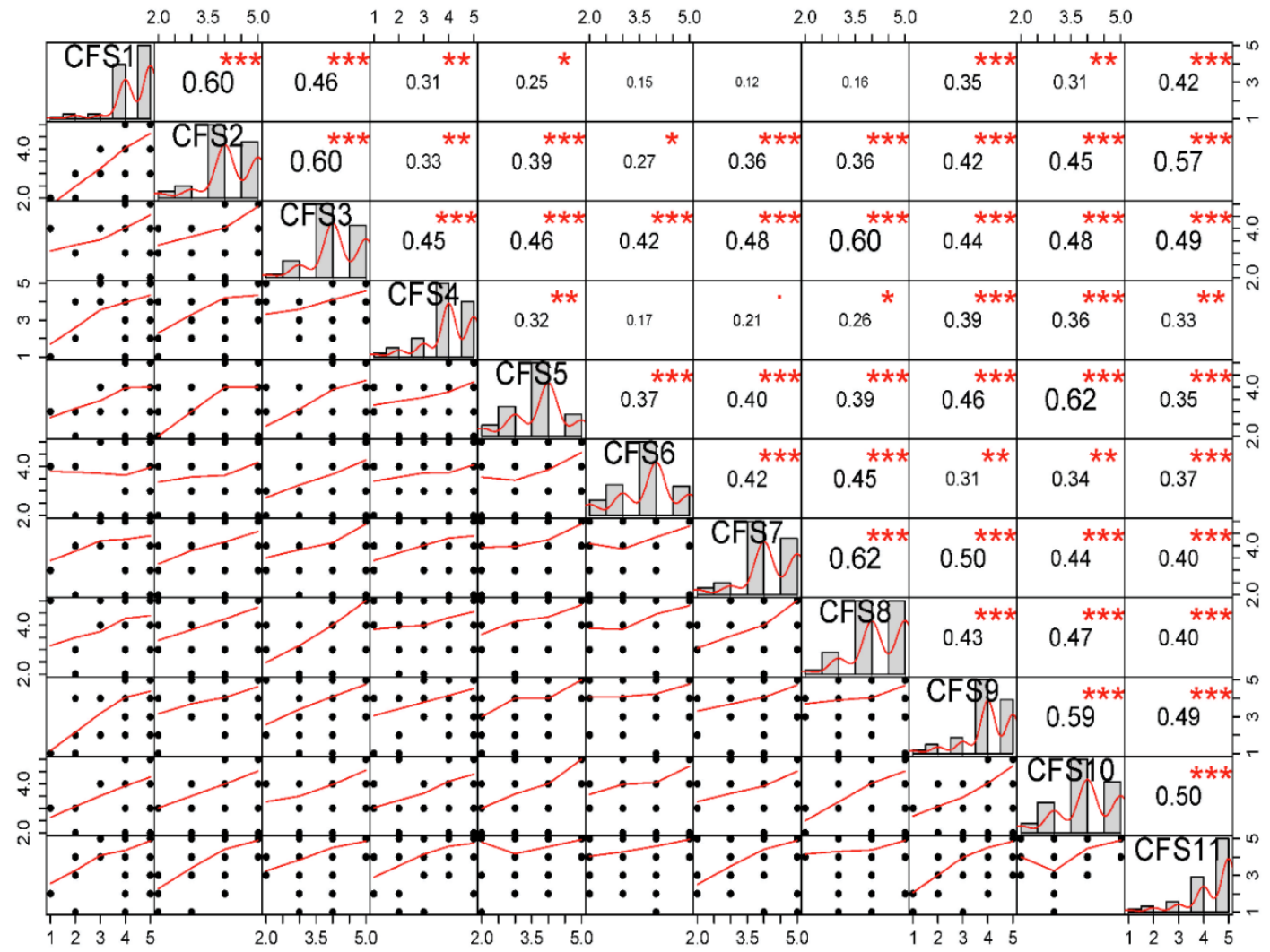

Figure 1: Correlations among CSFs (Spearman correlation coefficients) 
In the visualised correlation matrix in Figure 1, the distribution of each variable is shown on the diagonal. The histograms illustrating the distributions support the assumption regarding the nonnormal distributions for the variables in the dataset. On the bottom of the diagonal the bivariate scatter plots with a fitted line are displayed, while on the top of the diagonal the value of the correlations plus the significance level as stars are demonstrated. Thus, significance levels as $p-$ values $0.00,0.001,0.01$, and 0.05 are accordingly associated with “***”, “***”, “*” and ".." According to the rule of thumb for interpreting bivariate correlation coefficients proposed by Hinkle, Wiersma and Jurs (2003), coefficients greater than 0.50 indicate a moderate strength for the associations between two variables. Correlations in the range of $0.30-0.50$ are indicative of a low-level strength and are not of great value in practical terms.

In light of the strength of the correlation coefficients as illustrated in Figure 1, the strongest associations $(r h o(85)=0.62)$ were spotted between "Attempting to deliver projects systematically" and "Promoting team working and effective communication among parties involved". The same level of strength for association was observed between "Incorporating IRMS among the strategic objectives of organisations involved in projects" and "Factoring in the costs of IRMS within project budgets". The visualisation of correlations in Figure 1, acknowledges the low impacts of CSF6 and CSF4, which were the only CFSs with lower than moderate associations with other CFSs. Strong associations ( $r h o(85)=0.50-0.60)$ were also found between the pairs CSF1-CSF2, CSF2-CSF11, CSF8-CSF3, CSF10-CSF11 and CSF9CSF10. The interpretations for these associations are discussed below.

\section{Discussions}

The model in Figure 2 integrates the findings pertaining to the most important identified CSFs $\left(1^{\text {st }}-6^{\text {th }}\right)$ in Table 3 with the strong detected associations as shown in Figure 1 . It is noteworthy of mentioning that links depicted in Figure 2 illustrate identified associations between the identified CSFs. Establishing the existence and direction of causal effects requires extensive investigations, which is beyond the objectives of the present study.

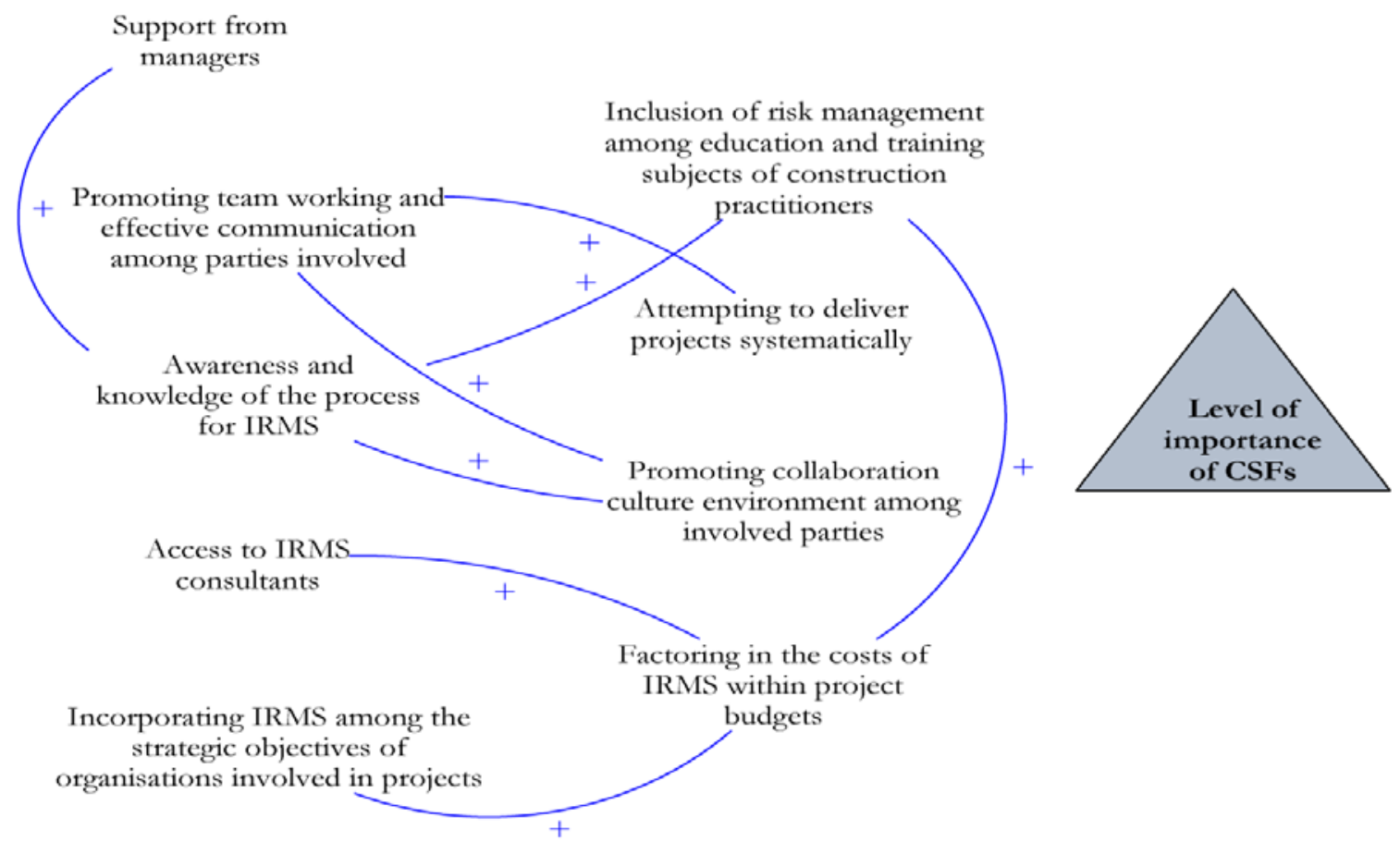

Figure 2: Summary of the most important CSFs and their associations 
As illustrated in Figure 2, the findings of the study emphasized the crucial role of support from managers as a prerequisite for implementing risk management on construction projects in a developing country. This resonates with the statement by Bowers and Khorakian (2014, p.33) according to which "...the attitude to risk management is largely dependent on the attitudes of high-level management...". On the other hand, support from managers was found to be strongly associated with their level of knowledge and awareness of the process of risk management implementation as shown in Figure 2. This highlights and corroborates the statement by Tadayon, Jaafar and Nasri (2012) arguing that knowledge and awareness is pivotal to risk management implementation in construction companies. Thus, the main issue to be addressed in order to enhance risk management implementation systems is to provide the necessary knowledge for high-ranked managers. Such a link between the levels of support from managers with the level of their knowledge is observed in all construction organisations in adopting a method or idea that is new to their system (Slaughter, 2000). This could be explained according to the model proposed by Hosseini et al. (2015) stating that available skills and level of awareness and knowledge in the construction industry are linked and both are pivotal for approval to implement a new or novel method. In essence, in the absence of knowledge, managers will evaluate risk management implementation as too difficult and demanding and will shy away from implementation in their projects. This is consistent with the observation made by Iqbal et al. (2015) in Pakistan which concluded that one major factor affecting risk management implementation was that decision makers in projects needed to have some knowledge and understanding of risk management.

As illustrated in Figure 2, "Inclusion of risk management among education and training subjects of construction practitioners" was the second most important factor and was strongly linked with the awareness and knowledge of risk management process. Clearly the need for considering training and education on risk management implementation is justified within the context of a developing country. This is especially so as the level of knowledge on systematic delivery of projects is low among construction practitioners in Iran as a developing country (Akhavan Tabassi and Bakar, 2009). It is evident that high-ranked managers in Iran, who are drawn usually from engineering backgrounds, lack the necessary knowledge of management and project management and this includes the awareness of risk management processes and procedures (Ghahramanzadeh, 2013). These results are consistent with literature from other developing countries (i.e. Pakistan see Table 1) which considered the importance of education and training. For example, Choudhry and Iqbal (2013) suggested that enhanced organisational knowledge on IRMS could also be achieved through training programs. This is corroborated by the findings of the study by Bowers and Khorakian (2014) which found that the level of knowledge of IRMS within the Iranian business environment was low, they suggested that additional training programs in IRMS were required.

The necessity of shifting towards systematic management and delivery of projects in Iran is illustrated in Figure 2. Support for such an insight is provided by Tadayon, Jaafar and Nasri (2012, p.68) stating "formal risk management identification and its relevant methods are infrequently used by the construction industry due to the absence of knowledge and proficiency."

The central impacts of "Promoting collaboration and culture environment among involved parties" is highlighted in Figure 2. This CSF was found to be strongly associated with increase in level of knowledge of managers, which was in turn consistent with the findings in previous studies e.g. (Choudhry and Iqbal, 2013; Goh and Abdul-Rahman, 2013; Ram and Corkindale, 2014). The two appear to reinforce each other as the closer collaboration enhances knowledge sharing of IRMS's within the industry. A major part of this is the process of transferring knowledge about implementing new methods and procedures in the construction industry from 
a more risk mature or early adopter organisation to a less mature or laggard organisation (Hosseini et al., 2015; Slaughter, 2000).

The study also brought to light the discrepancy between the perceptions of the two major parties involved (clients-consultants) with regards to CSF6 denoting the lack of attention of consultants to the working environment of projects. This can be explained by understanding the traditional systems of project delivery utilised in developing countries, where consultants are attached to the clients and act literally as the agents. They are therefore less likely to be affected by the changes in the working environment of the projects (Iqbal et al., 2015). In essence, in the traditional system of project delivery which is widespread in developing countries, contractors are the main party to be affected by risks (Perera et al., 2014). However, this outcome necessitates further investigation into possible discrepancies among different parties when it comes to risk management implementation. The findings showed that the CSFs identified by Chileshe and Kikwasi (2014) in Tanzania are not those perceived as important across the main parties within the construction industry of another developing country.

\section{Conclusion}

As one of the first studies in its kind, the present study investigates the CSFs for implementing risk management systems among construction organisations in a developing country. The results showed that support from high-ranked managers is a crucial precursor for higher level of risk management implementation across the industry. The remedial solution to this could be sought through effective management of knowledge on risk management implementation and shifting from traditional delivery of projects to a systematic and knowledge-oriented approach. Other identified important CSFs tended to reinforce this factor, in particular the: 'inclusion of risk management among education and training subjects of construction practitioners'; 'attempting to deliver projects systematically'; and 'awareness and knowledge of the process for implementing risk management'

This study, because it identifies the risks in developing countries utilising different methods, makes a number of important contributions to the risk management body of knowledge. Previous studies have failed to explore the main critical success factors for implementing of risk management systems in developing countries, nor have they identify the main causes for this lack of implementation. This research draws upon the study by Chileshe and Kikwasi (2014) and tests the application of their theories to a different context by taking their original theories regarding CSFs and applies them to a IRMS context This expands the body of knowledge as it applies to CSFs for IRMS within the construction industry in developing countries by validating the theories in another context as a contribution for a study (Fynes et al., 2015). The study also highlights the underlying associations between the effective knowledge management in construction organisations in developing countries and risk management implementation, providing a new perspective for addressing the problems associated with implementation of risk management in developing counties. This is novel to the risk management area and provides areas for future investigators. Nevertheless, one future area of research, which emerged out of the findings of the present study, is the need for future inquiries to devise plans for capitalising on the impacts of effective knowledge management, to enhance risk management implementation in developing countries.

The analyses also showed that the clients, contractors and consultants did not agree with regard to the overall ranking of the CSFs. In reference to the CSF 'impacts of the project environment', the findings showed significant differences between the perceptions of clients and of the consultants. According to Fynes et al. (2015) research studies greatly contribute through pointing out potential flaws in an existing theory when applied to another context. This is the case for the present study, as the findings revealed the fact that CSFs identified in Tanzania are not equally 
applicable to another developing country due to noticeable disagreement between the parties involved in projects.

As a corollary, the study provides a sound basis for researchers to customise identified CSFs for different parties involved in the construction industry in developing countries.

In practical terms, findings of this study contribute to raising the practitioner's awareness of the CSFs influencing the IRMS in developing countries. The findings provide a basis for managers and policy makers to promote training and educational plans associated with risk management, and would increase the level of support from managers and policy makers in the context of the prevailing conditions of the construction industry in developing economies.

Nevertheless, it is worth mentioning that responses are reflective of the perceptions of construction practitioners in Iran as a developing country, thus direct application of findings for other contexts should be treated with caution and should be considered after contextualisation of the findings to the natural context of the country at hand. Nevertheless, this also provides a fertile ground for future investigations on the area. A future area for research could therefore be to test the generalisability of these CSFs in other developing countries. A comparison of similar implementations of critical risk factors in risk management systems in the developed world is an obvious extension.

\section{References}

Akhavan Tabassi, A. and Bakar, A., 2009. Training, motivation, and performance: The case of human resource management in construction projects in Mashhad, Iran. International journal of project management, 27(5), pp.471-80. doi: http://dx.doi.org/10.1016/j.ijproman.2008.08.002

Akhavan Tabassi, A., Ramli, M., Roufechaei, K.M. and Akhavan Tabassi, A., 2014. Team development and performance in construction design teams: an assessment of a hierarchical model with mediating effect of compensation. Construction Management and Economics, 32(9), pp.932-49. doi: http://dx.doi.org/10.1080/01446193.2014.935739

Belassi, W. and Tukel, O.I., 1996. A new framework for determining critical success/failure factors in projects. International journal of project management, 14(3), pp.141-51. doi: http://dx.doi.org/10.1016/0263-7863(95)00064-X

Bentler, P.M. and Chou, C.-p., 1987. Practical Issues in Structural Modeling. Sociological Methods \& Research, 16(1), pp.78-117. doi: http://dx.doi.org/10.1177/0049124187016001004

Bowers, J. and Khorakian, A., 2014. Integrating risk management in the innovation project. European Journal of Innovation Management, 17(1), pp.25-40. doi: http://dx.doi.org/10.1108/EJIM-01-2013-0010

Brown, S. and Fallahi, A., 2008. Bam earthquake reconstruction assessment: an interdisciplinary analytical study on the risk preparedness of Bam and its cultural landscape: a world heritage property in danger. Structural Survey, 26(5), pp.387-99. doi: http://dx.doi.org/10.1108/02630800810922739

Byrne, B.M., 2001. Structural equation modeling with AMOS : basic concepts, applications, and programming. Mahwah, NJ: Lawrence Erlbaum Associates.

Cagliano, A.C., Grimaldi, S. and Rafele, C., 2015. Choosing project risk management techniques. A theoretical framework. Journal of Risk Research, 18(2), pp.232-48. doi: http://dx.doi.org/10.1080/13669877.2014.896398

Carless, S.A. and De Paola, C., 2000. The measurement of cohesion in work teams. Small group research, 31(1), pp.7188. doi: http://dx.doi.org/10.1177/104649640003100104

Chileshe, N. and Kikwasi, G.J., 2013, Reading, UK, 2-4 September: Association of Researchers in Construction Management.

Chileshe, N. and Kikwasi, G.J., 2014. Critical success factors for implementation of risk assessment and management practices within the Tanzanian construction industry. Engineering, Construction and Architectural Management, 21(3), pp.291-319. doi: http://dx.doi.org/10.1108/ECAM-01-2013-0001

Choudhry, R. and Iqbal, K., 2013. Identification of Risk Management System in Construction Industry in Pakistan. Journal of Management in Engineering, 29(1), pp.42-9. doi: http://dx.doi.org/10.1061/(ASCE)ME.1943$\underline{5479.0000122}$

Cronk, B.C., 2014. How to Use SPSS : a step-by-step guide to analysis and interpretation. 8th ed. Glendale, CA: Pyrczak Pub.

Ebrahimnejad, S., Mousavi, S.M. and Seyrafianpour, H., 2010. Risk identification and assessment for build-operatetransfer projects: A fuzzy multi attribute decision making model. Expert Systems With Applications, 37(1), pp.57586. doi: http://dx.doi.org/10.1016/j.eswa.2009.05.037 
Fallahi, A., 2008. Bam earthquake reconstruction assessment; An interdisciplinary analytical study on the risk preparedness of Bam and its cultural landscape: a World Heritage property in danger. Structural Survey, 26(5), pp.387-99. doi: http://dx.doi.org/10.1108/02630800810922739

Fereidouni, H.G., 2011. Factors contributing to the fluctuations in residential construction in Iran. Australasian Journal of Construction Economics and Building, 11(4), pp.77-86. doi: http://dx.doi.org/10.5130/ajceb.v11i4.2295

Forza, C., 2002. Survey research in operations management: a process-based perspective. International Journal of Operations \&amp; Production Management, 22(2), pp.152-94. doi: http://dx.doi.org/10.1108/01443570210414310

Frimpong, Y., Oluwoye, J. and Crawford, L., 2003. Causes of delay and cost overruns in construction of groundwater projects in a developing countries; Ghana as a case study. International journal of project management, 21(5), pp.321-6. doi: http://dx.doi.org/10.1016/S0263-7863(02)00055-8

Fynes, B., Professor Paul Coughlan, P., Boer, H., Holweg, M., Kilduff, M., Pagell, M., Schmenner, R. and Voss, C., 2015. Making a meaningful contribution to theory. International Journal of Operations \& Production Management, 35(9), pp.1231-52. doi: http://dx.doi.org/10.1108/IJOPM-03-2015-0119

Ghadak Zadeh, M., 2010. Risk management implementation in the iranian construction industry from contractors' perspective. Unpublished MSc thesis, Universiti Teknologi Malaysia.

Ghahramanzadeh, M., 2013. Managing Risk of Construction Projects A case study of Iran, University of East London.

Ghasemi, A. and Zahediasl, S., 2012. Normality tests for statistical analysis: a guide for non-statisticians. International journal of endocrinology and metabolism, 10(2), pp.486-9. doi: http://dx.doi.org/10.5812/ijem.3505

Ghoddousi, P., Poorafshar, O., Chileshe, N. and Hosseini, M.R., 2015. Labour productivity in Iranian construction projects: Perceptions of chief executive officers. International Journal of Productivity and Performance Management, 64(6), pp.811-30. doi: http://dx.doi.org/10.1108/IJPPM-10-2013-0169

Goh, C.S. and Abdul-Rahman, H., 2013. The Identification and Management of Major Risks in the Malaysian Construction Industry. Journal of Construction in Developing Countries, 18(1), pp.19-32.

Healey, J.F., 2008. Statistics : a tool for social research. 8th ed. Belmont, California: Wadsworth Cengage Learning.

Hinkle, D.E., Wiersma, W. and Jurs, S.G., 2003. Applied statistics for the behavioral sciences. 5th ed. Boston, Mass. : Houghton Mifflin

Holt, G.D., 2014. Asking questions, analysing answers: relative importance revisited. Construction Innovation: Information, Process, Management, 14(1), pp.2-16.

Hosseini, M.R., Chileshe, N., Zuo, J. and Baroudi, B., 2015. Adopting global virtual engineering teams in AEC Projects: A qualitative meta-analysis of innovation diffusion studies. Construction Innovation, 15(2), pp.151-79. doi: http://dx.doi.org/10.1108/CI-12-2013-0058

Ika, L.A., Diallo, A. and Thuillier, D., 2011. Critical success factors for World Bank projects: An empirical investigation. International journal of project management, 30(1), pp.105-16. doi: http://dx.doi.org/10.1016/j.ijproman.2011.03.005

Iqbal, S., Choudhry, R.M., Holschemacher, K., Ali, A. and Tamošaitienè, J., 2015. Risk management in construction projects. Technological and Economic Development of Economy, 21(1), pp.65-78. doi: http://dx.doi.org/10.3846/20294913.2014.994582

Jafari, M., Rezaeenour, J., Mahdavi Mazdeh, M. and Hooshmandi, A., 2011. Development and evaluation of a knowledge risk management model for project-based organizations: a multi-stage study. Management Decision, 49(3), pp.309-29. doi: http://dx.doi.org/10.1108/00251741111120725

Johnson, G. and Scholes, K., 1999. Exploring corporate strategy. 5th ed. London ; New York: Prentice Hall Europe.

KarimiAzari, A., Mousavi, N., Mousavi, S.F. and Hosseini, S., 2011. Risk assessment model selection in construction industry. Expert Systems With Applications, 38(8), pp.9105-11. doi: http://dx.doi.org/10.1016/j.eswa.2010.12.110

Kim, S. and Bejaj, D., 2000. Risk management in construction: An approach for contractors in South Korea. Cost Engineering, 42(1), pp.38-44.

Kog, Y. and Loh, P., 1999. Critical Success Factors for Different Project Objectives. Journal of Construction Engineering and Management, 125(3), pp.142-50. doi: http://dx.doi.org/10.1061/(ASCE)0733-9364(1999)125:3(142)

Lyons, T. and Skitmore, M., 2004. Project risk management in the Queensland engineering construction industry: a survey. International journal of project management, 22(1), pp.51-61. doi: http://dx.doi.org/10.1016/S02637863(03)00005-X

Marsick, V.J. and Watkins, K.E., 2003. Demonstrating the Value of an Organization's Learning Culture: The Dimensions of the Learning Organization Questionnaire. Advances in Developing Human Resources, 5(2), pp.132-51. doi: http://dx.doi.org/10.1177/1523422303005002002

Mojtahedi, S.M.H., Mousavi, S.M. and Makui, A., 2010. Project risk identification and assessment simultaneously using multi-attribute group decision making technique. Safety Science, 48(4), pp.499-507. doi: http://dx.doi.org/10.1016/i.ssci.2009.12.016

Parsizadeh, F. and Ghafory-Ashtiany, M., 2010. Iran public education and awareness program and its achievements. Disaster Prevention and Management: An International Journal, 19(1), pp.32-47. doi: http://dx.doi.org/10.1108/09653561011022126

Perera, B.A.K.S., Rameezdeen, R., Chileshe, N. and Hosseini, M.R., 2014. Enhancing the effectiveness of risk management practices in Sri Lankan road construction projects: A Delphi approach. International Journal of Construction Management, 14(1), pp.1-19. doi: http://dx.doi.org/10.1080/15623599.2013.875271 
Pinto, J.K. and Covin, J.G., 1989. Critical factors in project implementation: a comparison of construction and R\&amp;D projects. Technovation, 9(1), pp.49-62. doi: http://dx.doi.org/10.1016/0166-4972(89)90040-0

Pournader, M., Tabassi, A.A. and Baloh, P., 2015. A three-step design science approach to develop a novel human resource-planning framework in projects: the cases of construction projects in USA, Europe, and Iran. International journal of project management, 33(2), pp.419-34. doi: http://dx.doi.org/10.1016/j.ijproman.2014.06.009

Purdey, B., 2013. Occupant stimulus response workplace productivity and the vexed question of measurement. Facilities, 31(11/12), pp.505-20. doi: http://dx.doi.org/10.1108/F-03-2012-0021

Ram, J. and Corkindale, D., 2014. How "critical" are the critical success factors (CSFs)? Business Process Management Journal, 20(1), pp.151-74. doi: http://dx.doi.org/10.1108/BPMJ-11-2012-0127

Santoso, D.S., Ogunlana, S.O. and Minato, T., 2003. Assessment of risks in high rise building construction in Jakarta. Engineering, Construction and Architectural Management, 10(1), pp.43-55. doi: http://dx.doi.org/10.1108/09699980310466541

Slaughter, E.S., 2000. Implementation of construction innovations. Building Research \& Information, 28(1), pp.2-17. doi: http://dx.doi.org/10.1080/096132100369055

Tadayon, M., Jaafar, M. and Nasri, E., 2012. An Assessment of Risk Identification in Large Construction Projects in Iran. Journal of Construction in Developing Countries, 17(1), pp.57-69.

Zou, P.X.W. and Li, J., 2010. Risk identification and assessment in subway projects: Case study of Nanjing Subway Line 2. Construction Management and Economics, 28(12), pp.1219-38. doi: http://dx.doi.org/10.1080/01446193.2010.519781 